\title{
Differential Retinoic Acid Signaling in the Hippocampus of Aged Rats with and without Memory Impairment
}

\author{
Marta U. Wołoszynowska-Fraser, ${ }^{1}$ Sharyn L. Rossi, ${ }^{1}$ Jeffrey M. Long, ${ }^{1}$ Peter J. McCaffery, ${ }^{2}$ and \\ (1)Peter R. Rapp'
}

https://doi.org/10.1523/ENEURO.0120-21.2021

${ }^{1}$ Laboratory of Behavioral Neuroscience, Neurocognitive Aging Section, National Institute on Aging, Baltimore, MD 21224 and ${ }^{2}$ Institute of Medical Science, School of Medical Sciences, University of Aberdeen, Foresterhill, Aberdeen AB25 2ZD, Scotland, United Kingdom

\begin{abstract}
Retinoic acid (RA), a metabolite of vitamin A, has many physiological functions, and mounting evidence points to important roles in cognition. In vitro experiments indicate that RA is involved in homeostatic synaptic scaling in the hippocampus, which supports overall network stability during learning. It has been previously determined that disrupted RA signaling in the hippocampus causes deterioration of memory, that RA signaling declines with age in brain, and that application of RA reverses this decline. Here, we explore whether RA signaling is altered in an animal model of neurocognitive aging. We used a Morris water maze protocol to study cognitive decline in aged rats, which assesses hippocampus-dependent spatial memory and reveals substantial interindividual differences in aged animals. Aged unimpaired $(A U)$ rats perform on par with young $(Y)$, while aged impaired (Al) animals exhibit spatial memory deficits. We show that the major substrate for RA, retinol binding protein 4 (RBP4), is decreased in AU rats, and retinol cell surface receptor declines with chronological age. Other affected components of RA signaling include selective increases in Al animals in hippocampal synthesis (RALDH1) and catabolism of RA (CYP26B1), RA receptor $\alpha$, the RA regulated ionotropic glutamate receptor (GluR1), as well as fragile X mental retardation protein (FMRP). The results support the conclusion that, surprisingly, increased RA signaling in the aged hippocampus is associated with poor cognitive outcome.
\end{abstract}

Key words: aging; hippocampus; memory; retinoic acid; spatial; vitamin A

\section{Significance Statement}

Growing evidence indicates that retinoic acid (RA) function extends well beyond metabolic control and includes the regulation of memory-related synaptic plasticity. Here, we explore whether RA signaling is altered in an animal model of neurocognitive aging. We show that in fact RA function is altered at nearly all levels examined, and these results are unrelated to metabolic aging. Overall, the net effect points in the direction of increased RA signaling in impaired aged animals, which may contribute to disruption in excitation/inhibition balance, a prominent feature of age-related cognitive impairment and suspected early event in the pathogenesis of Alzheimer's disease.

Received March 22, 2021; accepted August 17, 2021; First published August 20, 2021.

P.J.M is non-executive director of Nevrargenics Ltd, a company developing synthetic retinoids for use in neurodegenerative disease. All other authors declare no competing financial interests.
Author contributions: M.U.W.-F., P.J.M., and P.R.R. designed research; M.U.W.-F., S.L.R., and J.M.L. performed research; M.U.W.-F. and J.M.L. analyzed data; M.U.W.-F., S.L.R., J.M.L., P.J.M., and P.R.R. wrote the paper. 


\section{Introduction}

Circulating levels of retinoic acid (RA), a metabolite of vitamin A (retinol), are dependent on dietary availability because animals are unable to synthesize retinol de novo. Dietary sources can be from plants in the form of carotenoids or animal sources (retinyl esters; Blomhoff and Blomhoff, 2006). RA has many physiological functions, including control of neuronal differentiation during development, and modulation of neuronal plasticity and neurogenesis in the adult hippocampus (Maden, 2007; Nomoto et al., 2012; Chen et al., 2014). A potential role in memory processes is emerging and RA supplementation as a potential intervention for successful cognitive aging has received preliminary support (Mingaud et al., 2008; Dumetz et al., 2020). Complementing these findings, retinol deficiency during adolescence causes memory impairments comparable to those seen in aged rodents, and vitamin A supplementation can reverse these deficits (Etchamendy et al., 2001; Bonnet et al., 2008). The age-related reduction of plasma retinol binding protein (RBP; Kocełak et al., 2018), and retinol (Van Der Loo et al., 2004), as well as decreased vitamin A metabolism (Touyarot et al., 2013), suggest an overall decrease in RA signaling in aging (Enderlin et al., 1997; Etchamendy et al., 2003; Das et al., 2014). A global diminishment in RA functions may link metabolic aging and neurobiological mechanisms responsible for age-associated cognitive decline.

In the blood, retinol circulates freely or bound to RBP4, which is carried by transthyretin (TTR). TTR allows stable transport of RBP4 bound retinol and prevents RBP4 filtration and degradation by the kidney (Kanai et al., 1968; Palha, 2002; Vieira and Saraiva, 2014). Circulating retinol enters the cell via stimulated by RA-6 (STRA6) receptor or, because of its lipophilic properties, via cell membrane diffusion (Napoli, 2012; O'Byrne and Blaner, 2013). Inside the cell, retinol binds to the cellular RBPs and is further metabolized to RA. The last step of RA synthesis is catalyzed by the retinaldehyde dehydrogenase enzymes (RALDHs). RA can exhibit genomic or non-genomic functions, via binding to RA receptors (RARs and RXRs), diffuse to neighboring cells, or be catabolized by the cytochrome p450 family enzymes (CYP26s; Chen and Napoli, 2008; Chen et al., 2008; Shearer et al., 2012).

The growth, development, and ability of neurons to adapt to a changing environment are crucial for normal cognition. Mounting evidence points to the involvement of RA in memory formation. RA is involved in homeostatic synaptic

This work was entirely supported by the Intramural Research Program of the National Institutes of Health, National institute on Aging.

Acknowledgements: We thank the members of the Neurocognitive Aging Section for expert technical support and valuable input throughout the course of this project.

M. U. Wołoszynowska-Fraser's present address: School of Life Sciences, Keele University, Keele Staffordshire, ST5 5BG, United Kingdom.

Correspondence should be addressed to Peter R. Rapp at rappp@mail.nih.gov. https://doi.org/10.1523/ENEURO.0120-21.2021

Copyright (C) 2021 Wołoszynowska-Fraser et al.

This is an open-access article distributed under the terms of the Creative Commons Attribution 4.0 International license, which permits unrestricted use, distribution and reproduction in any medium provided that the original work is properly attributed. scaling in the hippocampus, which maintains neuronal network stability in the face of learning-induced changes in synaptic strength (Groth and Tsien, 2008). This modulation is mediated through RA binding to its receptor $\alpha(\operatorname{RAR} \alpha)$, which acts as an RNA-binding granule (Maghsoodi et al., 2008), promoting the dissociation of ionotropic glutamate receptor (GluR1) mRNA bound to $\operatorname{RAR} \alpha$, making it available for translation. The fragile $X$ mental retardation protein (FMRP) is required for the translation of GluR1, which results in an increase of dendritic synthesis of GluR1 and synaptic strength (Aoto et al., 2008; Soden and Chen, 2010). The expression of glutamate receptors and glutamate uptake decline with age, potentially contributing to memory decline (Segovia et al., 2001; Yang et al., 2015).

To examine the link between hippocampal RA signaling and neurocognitive aging, we used a well-established animal model of age-related cognitive decline. In this model, the hippocampus in aged rats with spatial memory deficits displays a complex constellation of changes relative to younger animals and age-matched subjects with intact memory, including a decrease in the number of inhibitory somatostatin neurons in the dentate gyrus, increased basal Arc protein expression but diminished behavioral induction in the pyramidal cell fields, as well as pyramidal neuron hyperactivity in the CA3 region (Wilson et al., 2005; Spiegel et al., 2013; Fletcher et al., 2014). Here, we measured plasma RBP4 and protein levels of hippocampal STRA6 receptor, RA synthesizing and catabolizing enzymes, RAR $\alpha$, FMRP, and GluR1 in young $(\mathrm{Y})$ rats and aged animals with and without memory impairment.

\section{Materials and Methods}

\section{Animals}

Y (six months; $n=16)$ and aged (24 months; $n=32$ ) male Long-Evans rats (Charles River Laboratories) were single housed in a climate-controlled vivarium, on a 12/12 $\mathrm{h}$ light/dark cycle. Animals had ad libitum access to food (Teklad Global 18\% protein extruded rodent diet with vita$\min A$ acetate, $30 \mathrm{IU} / \mathrm{g}, 1 \mathrm{IU}=0.3 \mu \mathrm{g}$ retinol) and water. Rats were screened for health conditions, including skin conditions incompatible with water maze exposure, cataracts and tumors. Only healthy animals were used.

\section{Ethical statement}

This study was conducted in accordance with the recommendations in the Guide for the Care and Use of Laboratory Animals of the National Institutes of Health. The protocol was approved by the Animal Care and Use Committee of the National Institute on Aging (ASP number LBN-407-2020).

\section{Spatial learning and memory/background behavioral characterization}

Hippocampal-dependent spatial learning and memory were assessed using a Morris water maze protocol, optimized for documenting individual differences in aging (Gallagher et al., 1993). Briefly, animals were trained to find the location of a hidden platform, three trials per day over eight consecutive days. Probe trials 
were interpolated throughout training (one the last trial of every other day), to record spatial bias for the location of the platform. For the probes, the platform was unavailable for escape during the first $30 \mathrm{~s}$ of the trial. A learning index (LI) score for each animal was calculated based on average proximity (in centimeters) to the hidden escape location across the last three probe trials. Lower LI scores indicate better search accuracy focused on the escape location. Aged animals that performed on par with $Y$ were classified as aged unimpaired (AU), while aged animals that performed above an $\mathrm{LI}$ cutoff based on $Y$ were classified as aged impaired (AI). The cut off ( $\mathrm{LI}$ of 240) is based on the normative distribution of scores for many hundreds of $Y$ rats in previous research (Gallagher et al., 1993; Rapp and Gallagher, 1996; Maei et al., 2009; Haberman et al., 2012; Tomás Pereira and Burwell, 2015).

\section{Tissue collection}

Euthanasia for postmortem analysis occurred in the morning/early afternoon no sooner than two weeks after completing water maze training, to minimize the influence of behavioral testing on the RA measures of interest. Animals were disoriented or briefly anaesthetized using Isoflurane and decapitated. Trunk blood was collected in heparinized tubes, which were slowly inverted multiple times and placed on wet ice. Blood was transferred to Eppendorf tubes and spun at 1500 $\mathrm{G}$ for $20 \mathrm{~min}$ at $4^{\circ} \mathrm{C}$. Supernatant (plasma) was then transferred to a separate tube and both were kept at $-80^{\circ} \mathrm{C}$. Brains were extracted, and hippocampi were rapidly dissected over ice, snap frozen on dry ice, and stored at $-80^{\circ} \mathrm{C}$ until required.

\section{ELISA}

RBP4 ELISA was performed using a rat RBP4 kit (Abcam, ab203362). Plasma samples were diluted to 1:500,000, before performing the assay. A standard curve was created using stock RBP supplied and results were obtained by measuring the absorption at $450 \mathrm{~nm}$.

\section{Plasma glucose, triglyceride, and creatinine assays}

Plasma glucose levels were measured with an assay kit (Abcam, ab65333). Plasma samples were first deproteinized with 10-kDa spin columns (Abcam, ab93349). A standard curve was generated using stock glucose provided. The assay was run per manufacturer instructions and the absorption was measured at $570 \mathrm{~nm}$. Triglyceride content was tested using an assay kit (Biovision, \#622). Manufacturer's instructions were followed to obtain the standard curve from the triglyceride stock provided, the results were obtained by measuring the absorption at $570 \mathrm{~nm}$, and plasma triglyceride content was calculated. An assay kit was used to determine plasma creatinine content (Biovision, \#625). Deproteinized plasma samples were tested. Manufacturer instructions were followed, and stock creatinine was used to create a standard curve and absorption was read at $570 \mathrm{~nm}$.

\section{Protein extraction and quantification}

Proteins from one hippocampus per animal $(Y n=16$, aged $n=32$ ) were extracted using tissue protein extraction reagent (T-PER; Thermo Fisher Scientific) with HALT protease inhibitor cocktail (100×; Thermo Fisher Scientific), homogenized, sonicated, spun down for $20 \mathrm{~min}\left(13,200 \mathrm{rpm}\right.$ at $\left.4^{\circ} \mathrm{C}\right)$ and supernatant collected. Protein content in the supernatant was measured using Pierce's bicinchoninic acid (BCA) assay (Thermo Fisher Scientific). Proteins were made into stock solution of $5 \mathrm{mg} / \mathrm{ml}$.

\section{Synaptosome preparation}

Synaptic protein extraction reagent (Syn-PER; Thermo Fisher Scientific) was used to isolate synaptosomes, which contain key presynaptic and postsynaptic proteins. Briefly, $10 \mathrm{ml}$ of Syn-PER was added to each milligram of hippocampal tissue, which was then homogenized using Dounce homogenizer. Samples were then centrifuged at $3600 \mathrm{rpm}$ for $10 \mathrm{~min}$ at $4^{\circ} \mathrm{C}$. Supernatant was placed in a fresh tube and centrifuged again at $12700 \mathrm{rpm}$ for $20 \mathrm{~min}$ at $4^{\circ} \mathrm{C}$. Supernatant was then removed, and the pellet resuspended in Syn-PER (2 ml/g of tissue). Again, protein content was measured by BCA assay and made into $5 \mathrm{mg} / \mathrm{ml}$ stock solution.

\section{Western blotting}

Samples (25 mg of protein per well/lane) were separated by SDS-PAGE Bis-Tris gel (Invitrogen) and MESSDS buffer (Invitrogen). All groups (Y, AU, and Al) were represented within each gel. Following separation, proteins were transferred onto PVDF membranes (Invitrogen) using an iBlot dry blotting system (Invitrogen). The antibodies were diluted in blocking solution (2\% ELC advance blocking agent; GE Healthcare) in wash buffer (TBS and $0.1 \%$ Tween 20 ) and membranes were incubated overnight at $4^{\circ} \mathrm{C}$. Immunoreactivity was detected by application of conjugated secondary antibodies (Alexa Fluor 488; Alexa Fluor 546; CY5; Jackson ImmunoResearch). The immunoblots were scanned on a Sapphire imager (Azure Biosystems) at $100-\mathrm{mm}$ resolution and quantified using ImageJ software (National Institutes of Health). Glyceraldehyde 3-phosphate dehydrogenase (GAPDH) or $\beta$-actin were used as loading controls and all results were normalized to the expression of these proteins.

\section{Primary antibodies}

The primary antibodies and their dilutions are listed in Table 1.

\section{Statistical analysis}

Statistical analysis was performed using Prism 7.0 (GraphPad Software). Unless otherwise stated, unpaired two-tailed Student's $t$ test was used when comparing two groups, while two-way ANOVA with Tukey's multiple comparison test was applied to multiple group analysis. Pearson $r$ correlation coefficients were calculated to investigate associations between variables of interest. Values of $p<0.05$ were considered statistically significant. An observation was considered an outlier if its value 
Table 1: Primary antibodies used for the Western blotting (WB) with corresponding dilutions

\begin{tabular}{llllll}
\hline Antibody name & Host & WB dilution & Predicted molecular weight & Supplier & Catalog number \\
\hline Anti-RALDH1 & Goat & $1: 3000$ & $55 \mathrm{kDa}$ & Abcam & ab9883 \\
Anti-RALDH3 & Rabbit & $1: 1000$ & $57 \mathrm{kDa}$ & Abcam & Bb129815 \\
Anti- $\beta$-actin & Mouse & $1: 30,000$ & $45 \mathrm{kDa}$ & BioVision Incorporated & Santa Cruz Biotechnology \\
Anti-CYP26A1 & Mouse & $1: 1000$ & $49 \mathrm{kDa}$ & ProteinTech Antibodies & $21555-1-A P$ \\
Anti-CYP26B1 & Rabbit & $1: 1000$ & $58-60 \mathrm{kDa}$ & Abcam & ab17722 \\
Anti-FMRP & Rabbit & $1: 1000$ & $80 \mathrm{kDa}$ & Santa Cruz Biotechnology & sc-25778 \\
Anti-GAPDH & Rabbit & $1: 10,000$ & $37 \mathrm{kDa}$ & ThermoFisher Scientific & PA1-46151 \\
Anti-GluR1 & Rabbit & $1: 500$ & $106 \mathrm{kDa}$ & Millipore & AB9708 \\
Anti-PSD95 & Rabbit & $1: 250(\mathrm{~s})$ & & Abcam & ab28767 \\
Anti-RAR $\alpha$ & Goat & $1: 500$ & $95 \mathrm{kDa}$ & ProteinTech Antibodies & $22001-1-A P$ \\
Anti-Stra6 & Rabbit & $1: 1000(\mathrm{~s})$ & $51 \mathrm{kDa}$ & &
\end{tabular}

(s), synaptosome preparation

was $>2$ SDs from the mean. This was the case for only one $Y$ animal, which was excluded from the RALDH1 analysis.

\section{Results}

\section{Aged rats display increased individual differences in spatial memory}

Spatial memory was assessed in the Morris water maze using a protocol optimized for the study of cognitive aging (Gallagher et al., 1993). Over the course of testing rats were given probe trials to assess spatial bias for the platform location, and LI scores were calculated for each animal. As predicted, aged animals, on average displayed higher LI scores YY mean $=182.3(n=16)$, aged mean $=239.1(n=32), t_{(46)}=$ 4.537, $p<0.0001$; Fig. $1 A]$. Consistent with many earlier studies (Lee et al., 2005; Castellano et al., 2012; Fletcher et al., 2014; Myrum et al., 2019), the aged group exhibited substantially increased variability such that some rats performed on par with Y, while others performed well outside the normal range. Aged animals with LI scores below $240(n=15)$ were classified as AU, and rats that scored above $240(n=17)$ were operationally defined Al. This animal model provides an opportunity to test for chronological age effects ( $Y$ vs aged), while also allowing the study of mechanisms of cognitive aging, by comparing the $\mathrm{Y}, \mathrm{AU}$, and $\mathrm{Al}$, and exploring potential linear correlations between LI scores and RA signaling factors in the same subjects.

\section{Plasma RBP4 is reduced in aged animals without memory impairment}

Retinol can circulate free in blood or bound to RBP4/ TTR complex. We tested plasma RBP4 concentration,
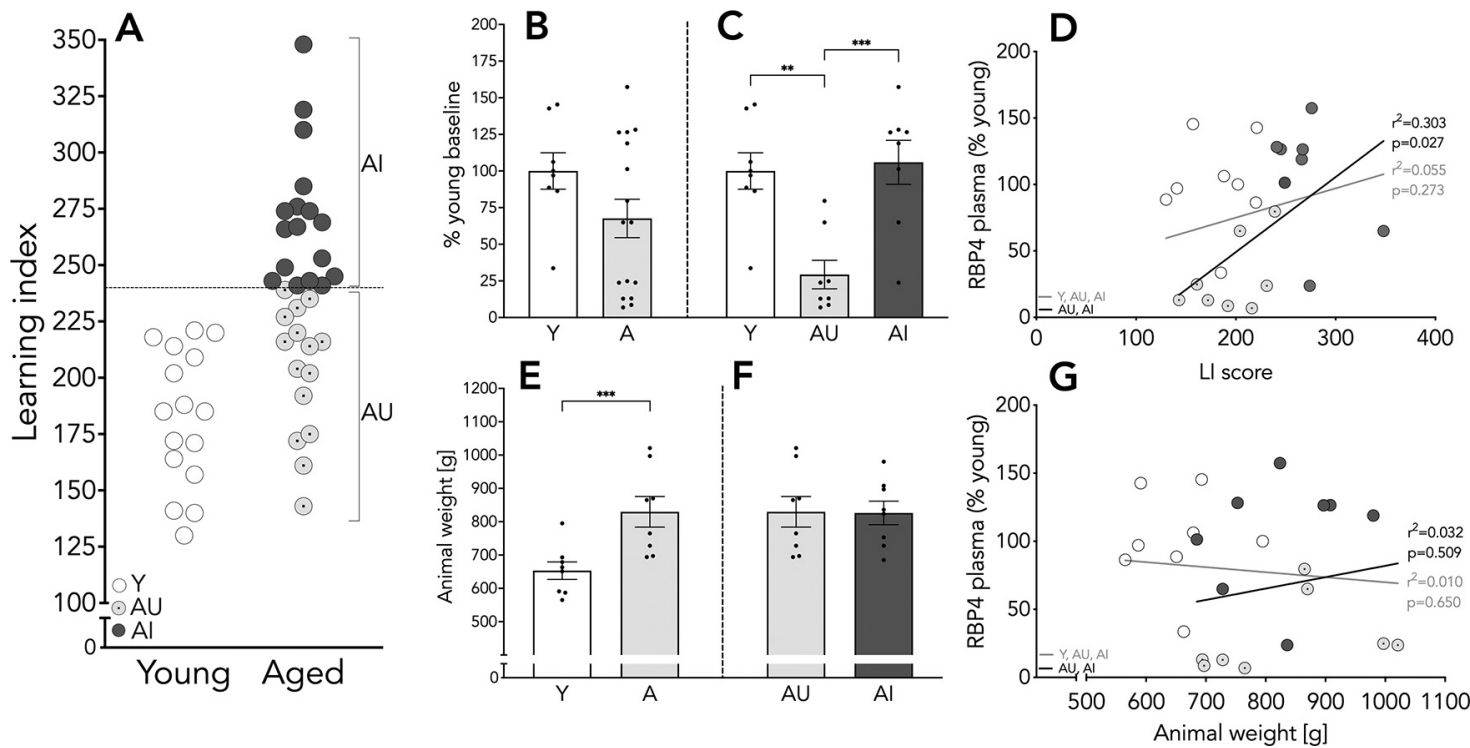

Figure 1. Spatial memory performance, animal weight, and plasma RBP4 levels. LI scores for individual $Y$ and aged animals (A); plasma RBP4 levels presented as \% of $\mathrm{Y}$ baseline $(\boldsymbol{B}, \boldsymbol{C})$; correlation of plasma RBP4 and LI score (D); mean body weights of animals tested. Note that body weight did not differ among the aged rats (E, $\boldsymbol{F})$; correlation of plasma RBP4 and body weight (G). Results shown as bars with individual animal data plotted. Statistical analysis, unpaired two-tailed Student's $t$ test $(\boldsymbol{B}, \boldsymbol{E}, \boldsymbol{F})$, oneway ANOVA, with Tukey's multiple comparisons test $(\boldsymbol{C})$, and linear regression $(\boldsymbol{D}, \mathbf{G}$; all animals, gray line; aged animals, black line); ${ }^{* *} p<0.01,{ }^{* *} p<0.001$. Y $n=16$ and aged $n=32$ (AU $n=15$, Al $n=17$; panel $A$ ); Y $n=8$ and aged $n=16$ (AU $n=8$, Al $n=8$; panels B-G). Error bars represent SEM. 


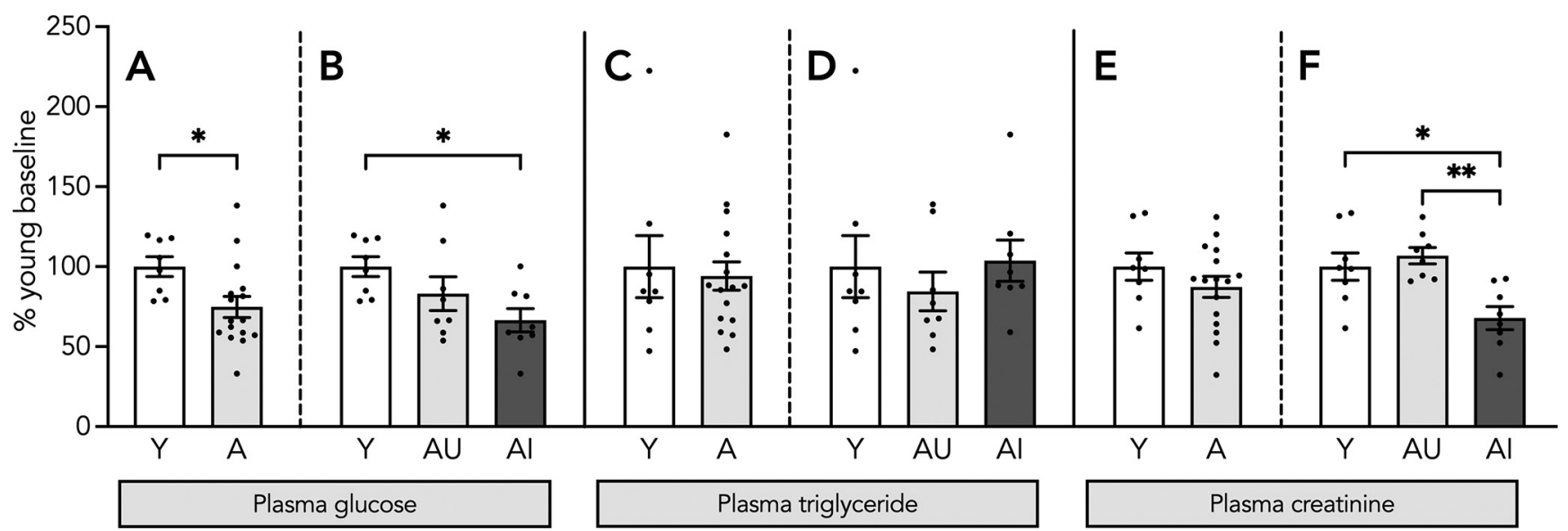

Figure 2. Plasma glucose, triglyceride, and creatinine levels. Levels of plasma glucose $(\boldsymbol{A}, \boldsymbol{B})$ triglyceride $(\boldsymbol{C}, \boldsymbol{D})$, and creatinine $(\boldsymbol{E}, \boldsymbol{F})$ in the $\mathrm{Y}$, aged, $\mathrm{AU}$, and Al groups. Results shown as bars with individual animal data plotted. Statistical analysis, unpaired twotailed Student's $t$ test $(\boldsymbol{A}, \boldsymbol{C}, \boldsymbol{E})$, and one-way ANOVA, with Tukey's multiple comparisons test $(\boldsymbol{B}, \boldsymbol{D}, \boldsymbol{F}) ;{ }^{*} p<0.05,{ }^{* \star} p<0.01$. Y $n=8$ and aged $n=16$ (AU $n=8, \mathrm{Al} n=8$; all panels). Error bars represent SEM.

which is indicative of retinol availability. We found no differences in plasma RBP4 between the $Y$ and aged groups $\left(t_{(22)}=1.568, p=0.131\right.$; Fig. 1B). However, RBP4 levels were significantly lower in $\mathrm{AU}$ compared with $\mathrm{Y}$ and $\mathrm{Al}$ rats $\left(F_{(2,21)}=11.48, p=0.0004 ; \mathrm{Y}\right.$ vs $\mathrm{AU} p=0.0019 ; \mathrm{AU}$ vs Al $p=0.0009$; Fig. $1 C$ ). Additionally, levels of circulating RBP strongly correlated with spatial memory performance among the aged rats such that subjects with higher RBP4 levels displayed worse spatial memory $\left(n=16, r^{2}=0.303\right.$, $p=0.027$; Fig. $1 D$, black line). The correlation was not significant when the data for $Y$ rats were included in the analysis $\left(n=24, r^{2}=0.055, p=0.273\right.$; Fig. $1 D$, gray line), suggesting that coupling between RBP4 availability and hippocampal memory function emerges specifically in relation to cognitive aging.

Although the liver is the major peripheral source of RBP4, it is also released by adipocytes (Thompson et al., 2017), and elevated RBP4 levels have been reported in obese and diabetic individuals (Yang et al., 2005; Esteve et al., 2009). Since aged rats are heavier than $Y$ adults $(Y$ mean $=653 \mathrm{~g}$, aged mean $=828 \mathrm{~g}, t_{(22)}=3.979, p=0.0006$; Fig. $1 E$ ) we examined whether RBP4 levels correlate with body weight. In the aged group there was no difference in body weight between $A U$ and Al rats $\left(t_{(14)}=0.06, p=0.95\right.$; Fig. 1F). RBP4 levels were unrelated to body weight in $Y$ and aged animals considered together ( $n=24, r^{2}=0.01, p=0.65$; Fig. 1G, gray line), and no correlation between body weight and RBP levels was detected when $\mathrm{AU}$ and $\mathrm{Al}$ rats were considered alone $\left(n=16, r^{2}\right.$ $=0.032, p=0.032$; Fig. $1 G$, black line). These results indicate that RBP4 levels in aging are more tightly linked with individual differences in cognitive outcome than with the effects of chronological age, per se.

\section{Aged Long-Evans rats do not display metabolic syndrome}

Plasma glucose, triglyceride and creatinine content were measured to determine whether aged animals display metabolic symptoms that might affect RBP4 levels. Plasma glucose was significantly lower in aged animals compared with $\mathrm{Y}\left(t_{(22)}=2.445, p=0.023\right.$; Fig. $\left.2 A\right)$. This difference was especially prominent when Al rats were compared with $\mathrm{Y}\left(F_{(2,21)}=4.155, p=0.03 ; \mathrm{Y}\right.$ vs Al, $p=0.023$; Fig. $2 B)$, but not with $A \cup(p=0.34)$. Thus, despite substantially increased weight, pancreatic function seems to keep glucose levels on par with, or lower than, in $Y$ rats compared with $\mathrm{AU}$ and $\mathrm{Al}$ animals. Plasma triglyceride content was measured to test liver function, and the results showed no difference between $Y$ and aged animals $\left(t_{(22)}=\right.$ $0.319, p=0.75$; Fig. $2 C$ ), or when aged rats were split depending on their cognitive profile $\left(F_{(2,21)}=0.454, p=0.64\right.$; Fig. 2D). Kidney function was assessed indirectly via plasma creatinine levels. Subjects with chronic kidney disease often display increased circulating RBP4 (Kocełak et al., 2018; Xun et al., 2018). We saw no differences in plasma creatinine levels between $Y$ and aged rats $\left(t_{(22)}=1.133\right.$, $p=0.27$; Fig. 2E). However, we found significantly lower plasma creatinine in Al group compared with $Y$ and $A U$ rats $\left(F_{(2,21)}=8.59, p=0.002 ; \mathrm{Y}\right.$ vs Al, $p=0.0116 ; \mathrm{AU}$ vs Al, $p=0.002$; Fig. 2F). These data taken together indicate that the RBP4 results in aged rats are not a secondary consequence metabolic disease.

\section{Hippocampal STRA6 receptor expression is reduced in aged animals}

STRA6 is a cell surface receptor by which retinol enters the cell. We measured protein expression of this RA receptor in whole hippocampus from $\mathrm{Y}$ and aged animals. Levels of STRA6 were significantly lower in aged animals compared with $Y\left(t_{(22)}=6.00, p<0.0001\right.$; Fig. $\left.3 B\right)$. This was true for aged rats without and with spatial memory impairment $\left(F_{(2,21)}=17.40, p<0.0001 ; \mathrm{Y}\right.$ vs AU $p<0.0001 ; \mathrm{Y}$ vs Al, $p=0.0002$; Fig. $3 C$ ). Moreover, hippocampal STRA6 protein levels did not differ between the aged subgroups (Fig. $3 C$ ) or correlate with memory performance $\left(Y\right.$ and aged: $n=24, r^{2}=$ $0.0 .121, p=0.096$; aged only: $n=16, r^{2}=0.010 p=0.148$ ). These results indicate that, independent of cognitive outcome, hippocampal aging is associated with a reduction of the receptor allowing retinol cell entry. 
A
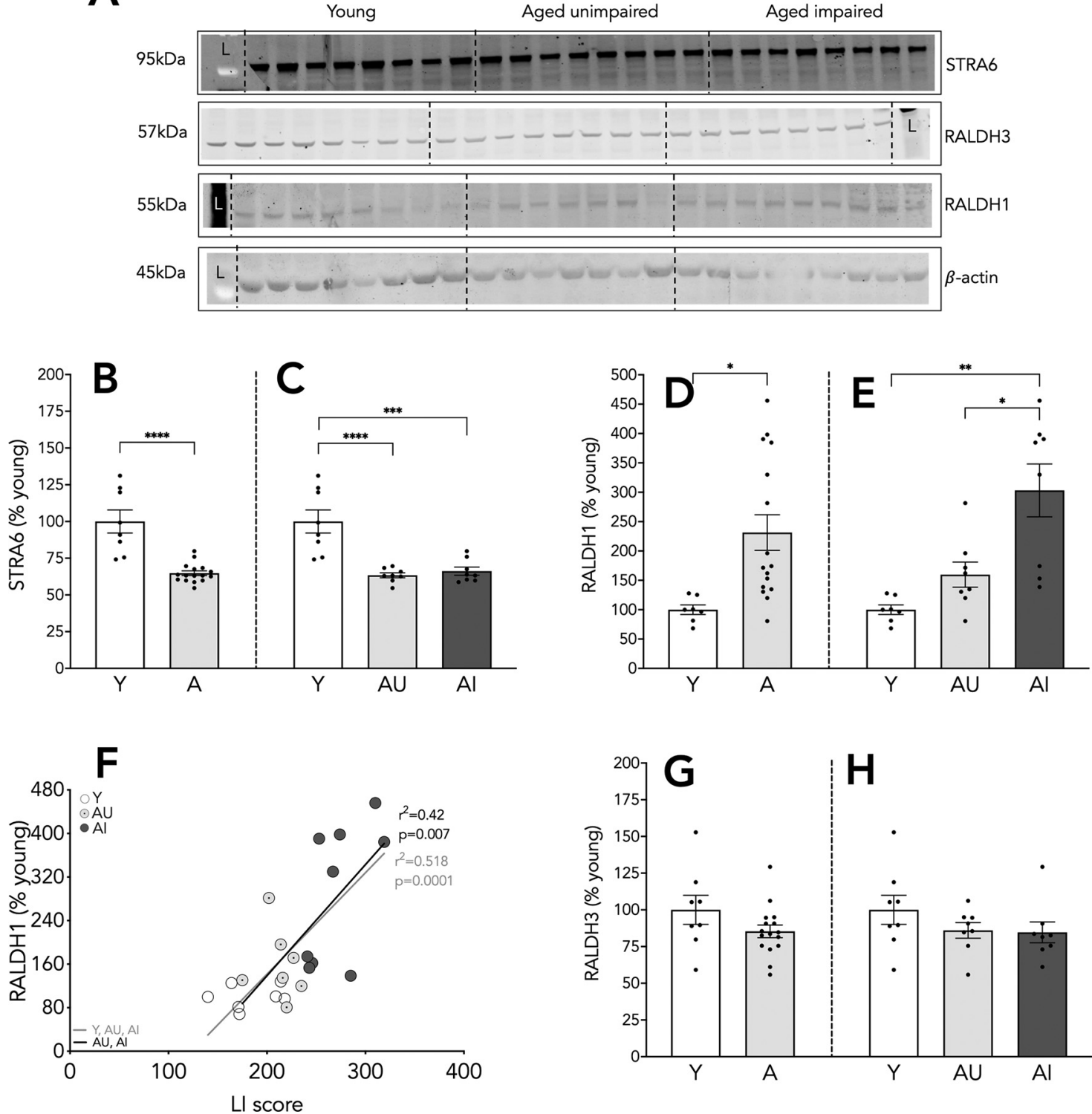

Figure 3. Protein expression of STRA6, RALDH1, and RALDH3 in the hippocampus. Representative blots for proteins of interest (A), expression relative to $\beta$-actin as a percentage of $Y$ values, $L$ stands for molecular ladder lane. Hippocampal expression of STRA6 $(\boldsymbol{B}, \boldsymbol{C}), \operatorname{RALDH} 1(\boldsymbol{D}, \boldsymbol{E})$, and RALDH3 $(\boldsymbol{G}, \boldsymbol{H})$. Correlation of protein expression of RALDH1 and LI scores $(\boldsymbol{F})$. Results shown as bars with individual animal data plotted. Statistical analysis, unpaired two-tailed Student's $t$ test $(\boldsymbol{B}, \boldsymbol{D}$, G), one-way ANOVA, with Tukey's multiple comparisons test $(\boldsymbol{C}, \boldsymbol{E}, \boldsymbol{H})$, and linear regression $\left(\boldsymbol{F}\right.$; all animals, gray line; aged animals, black line); ${ }^{*} p<0.05,{ }^{* \star} p<0.01$, ${ }^{* * *} p<0.001,{ }^{* * *} p<0.0001$. Y $n=8$ and aged $n=16$ (AU $n=8$, Al $\left.n=8 ; \boldsymbol{B}, \boldsymbol{G}, \boldsymbol{H}\right) ; \mathrm{Y} n=7$ and aged $n=16(\mathrm{AU} n=7, \mathrm{Al} n=9 ; \boldsymbol{D}-\boldsymbol{F}$ ). Error bars represent SEM.

\section{RA synthesis is increased in Al rats}

The last step of RA metabolism is catalyzed by the RALDH enzymes. Here, we assessed the protein expression of two RALDH enzymes in whole hippocampal preparations, RALDH1 and RALDH3. Significantly higher levels of RALDH1 protein were found in aged rats relative to $Y\left(t_{(22)}=2.805\right.$, $p=0.011$; Fig. 3D). This was the case only for Al, in which hippocampal RALDH1 expression was significantly higher than in both $\mathrm{Y}$ and $\mathrm{AU}$ animals $\left(F_{(2,20)}=9.314, p=0.001 ; \mathrm{Y}\right.$ vs $\mathrm{Al}$ $p=0.001$; AU vs Al $p=0.026$; Fig. $3 E$ ). Notably, the expression of this enzyme correlated with $\mathrm{LI}$ scores among the aged animals such that rats with higher RALDH1 expression scored more poorly (i.e., higher LI scores; $n=16, r^{2}=0.42$, $p=0.007$; Fig. $3 F$, black line). The correlation was similar when the $\mathrm{Y}$ and aged animals are considered together $\left(n=23, r^{2}=0.518, p=0.0001\right.$; Fig. $3 F$, gray line). RALDH3 protein expression in whole hippocampus was comparable in the $Y$ and aged groups $\left(t_{(22)}=1.593, p=0.125\right.$; Fig. $\left.3 G\right)$ and unrelated to cognitive status $\left(F_{(2,21)}=1.22, p=0.315\right.$; Fig. $\left.3 H\right)$. In the aggregate, the results indicate that RALDH1 driven RA synthesis is potentially increased in the hippocampus of $\mathrm{Al}$ rats. 

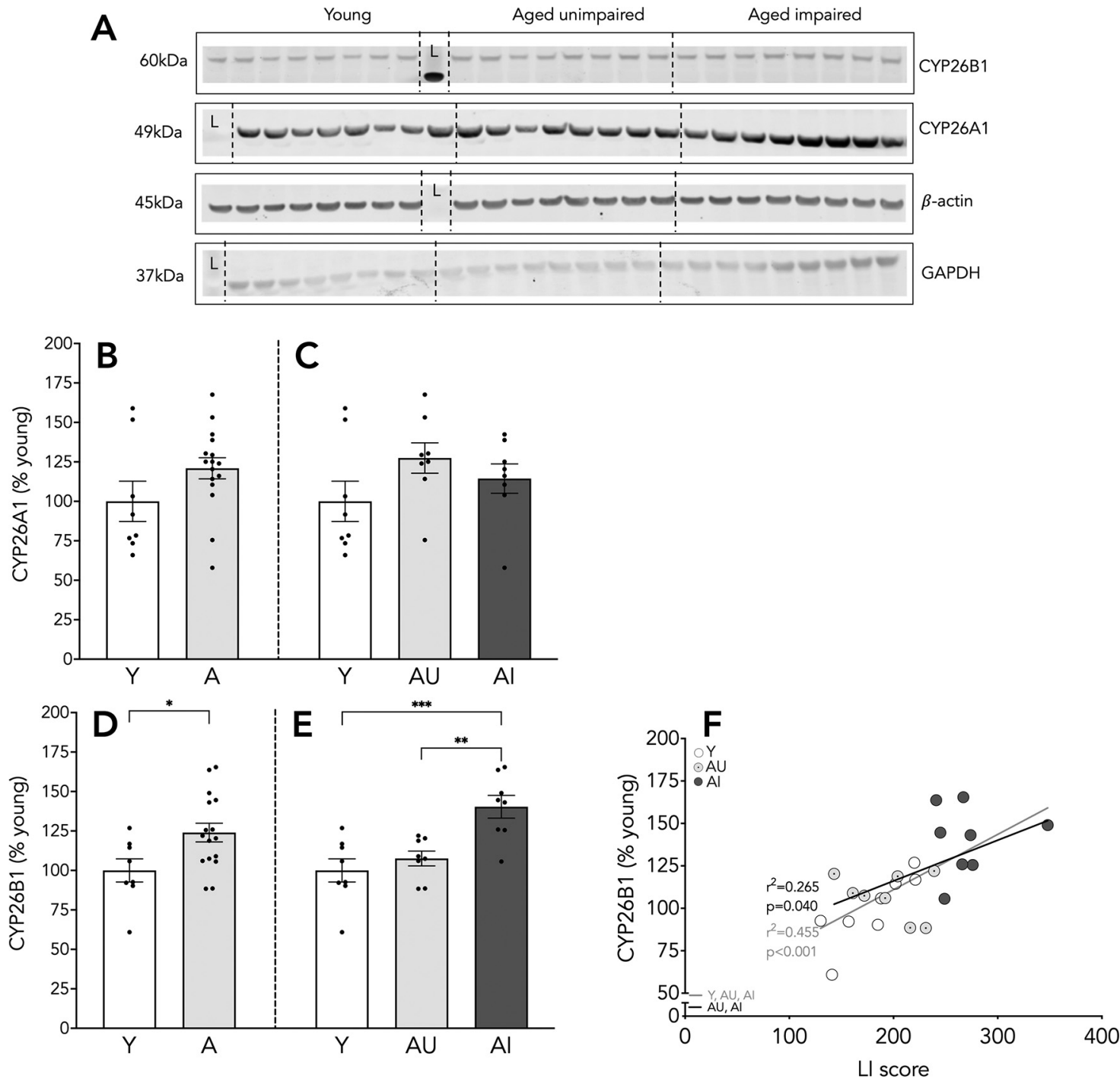

Figure 4. Protein expression of RA catabolizing enzymes in the hippocampus. Representative blots for proteins of interest (A), CYP26A1 expression relative to GAPDH, CYP26B1 expression relative to $\beta$-actin, $L$ stands for molecular ladder lane. Hippocampal expression of CYP26A1 $(\boldsymbol{B}, \boldsymbol{C})$ and CYP26B1 $(\boldsymbol{D}, \boldsymbol{E})$. Correlation of CYP26B1 levels and LI scores $(\boldsymbol{F})$. Results shown as bars with individual animal data plotted. Statistical analysis, unpaired two-tailed Student's $t$ test $(\boldsymbol{B}, \boldsymbol{D})$, one-way ANOVA, with Tukey's multiple comparisons test $(\boldsymbol{C}, \boldsymbol{E})$, and linear regression $\left(\boldsymbol{F}\right.$; all animals, gray line; aged animals, black line); ${ }^{*} p<0.05,{ }^{* \star} p<0.01,{ }^{* \star \star} p<0.001$. $\mathrm{Y} n=8$ and aged $n=16(\mathrm{AU} n=8, \mathrm{Al} n=8 ; \boldsymbol{B}-\boldsymbol{F})$. Error bars represent SEM.

\section{Al animals display increased RA catabolism}

RA is catabolized by the family of cytochrome p450 enzymes, CYP26. We measured the protein expression of CYP26A1 and CYP26B1 enzymes in the whole hippocampus preparations. CYP26A1 protein expression was largely overlapping between $Y$ and aged rats $\left(t_{(22)}=1.609\right.$, $p=0.122$; Fig. $4 B$ ) without and with spatial memory deficits $\left(F_{(2,21)}=1.651, p=0.216\right.$; Fig. $\left.4 C\right)$. In contrast, we detected significantly higher CYP26B1 protein expression in the aged hippocampus $\left(t_{(22)}=2.428, p=0.024\right.$; Fig. $\left.4 D\right)$. Interestingly, CYP26B1 levels were selectively increased in $\mathrm{Al}$, differing from both $\mathrm{Y}$ and $\mathrm{AU}$ rats $\left(F_{(2,21)}=10.85\right.$, $p=0.0006$; Y vs Al $p=0.0007$; AU vs Al $p=0.005$; Fig. $4 E$; levels in the latter groups were equivalent. Furthermore, there was a strong correlation between the expression of CYP26B1 and cognitive performance in the $Y$ and aged rats $\left(n=24, r^{2}=0.455, p=0.0003\right.$; Fig. $4 F$, gray line), which was also robust among the aged animals alone ( $n=16, r^{2}=0.265, p=0.040$; Fig. $4 F$, black line), such that poor spatial memory was coupled with higher CYP26B1 enzyme levels. These results suggest that, although age-related increases in RA catabolism are selectively observed in aged animals with memory impairment, catabolic enzyme levels are coupled with spatial memory across the full range of individual differences observed in both $\mathrm{Y}$ and aged rats.

\section{Cellular and synaptosome RAR $\alpha$ expression is increased in Al rats}

RAR $\alpha$ is one of six RA receptors but the only one that regulates homeostatic plasticity via non-nuclear action 

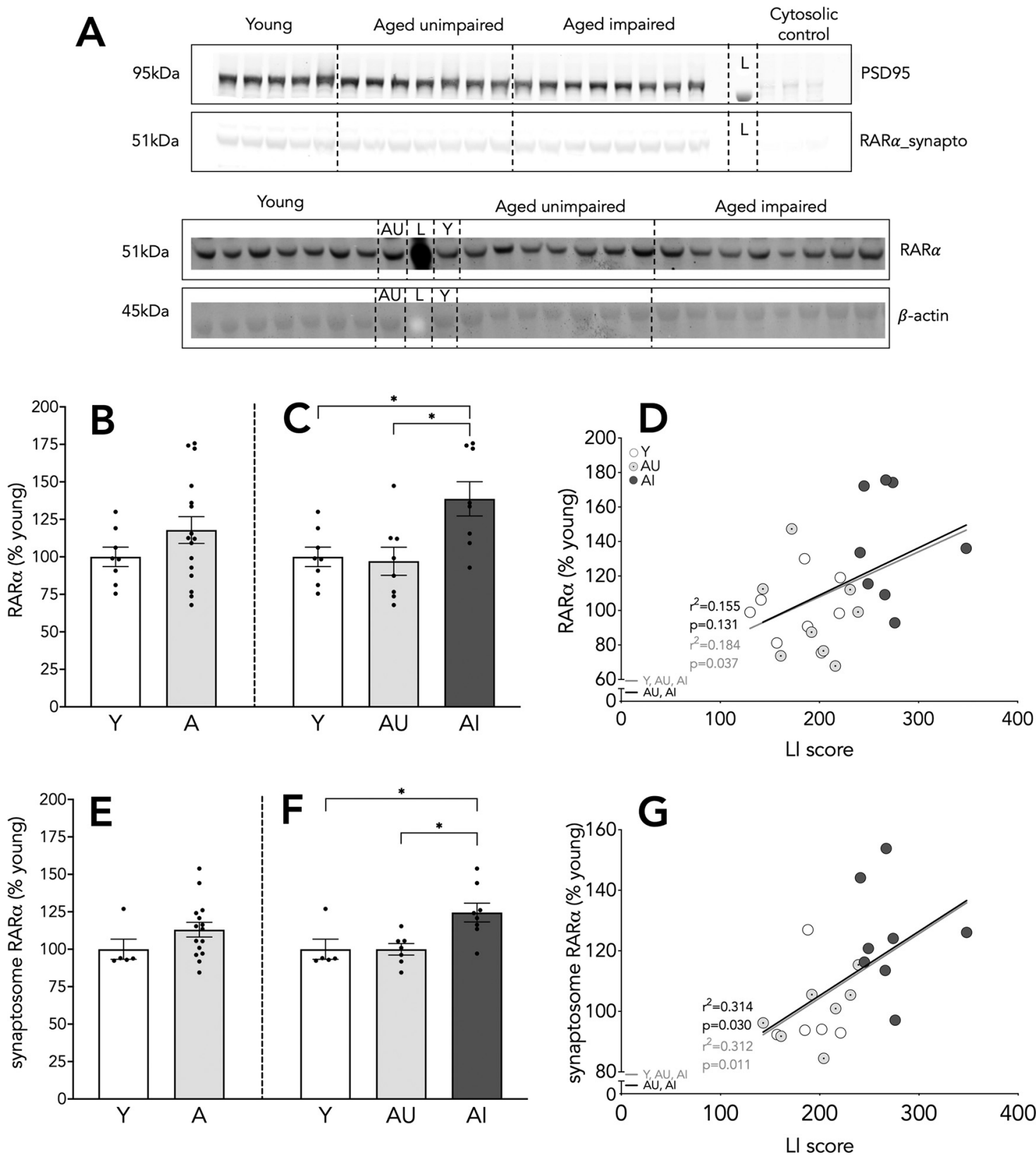

Figure 5. Cellular and dendritic RAR $\alpha$ expression in the hippocampus. Representative blots for RAR $\alpha(\boldsymbol{A})$, cellular RAR $\alpha$ expression relative to $\beta$-actin (bottom two panels), and synaptosome RAR $\alpha$ expression relative to PSD95 (top two panes); L stands for molecular ladder lane. Cytosolic fraction included as a confirmation of the fractionation. Hippocampal expression of RAR $\alpha(\boldsymbol{B}, \boldsymbol{C})$. Correlation of RAR $\alpha$ protein levels with LI scores $(\boldsymbol{D})$. Synaptosome compartment RAR $\alpha$ content $(\boldsymbol{E}, \boldsymbol{F})$. Correlation of synaptosome $\mathrm{RAR} \alpha$ levels and LI scores (G). Results shown as bars with individual animal data plotted. Statistical analysis, unpaired two-tailed Student's $t$ test $(\boldsymbol{B}, \boldsymbol{E})$, one-way ANOVA, with Tukey's multiple comparisons test $(\boldsymbol{C}, \boldsymbol{F})$, and linear regression $(\boldsymbol{D}$, $\boldsymbol{G}$; all animals, gray line; aged animals, black line); C, cytosolic fraction; ${ }^{*} p<0.05$. Y $n=8$ and aged $n=16(\mathrm{AU} n=8, \mathrm{Al} n=8 ; \boldsymbol{B}-\boldsymbol{D}) ; \mathrm{Y} n=5$ and aged $n=15$ (AU $n=7, \mathrm{Al} n=8 ; \boldsymbol{E}-\mathbf{G})$. Error bars represent SEM.

(Aoto et al., 2008; Yang et al., 2015). This receptor is involved in homeostatic synaptic scaling through its interaction with FMRP and GluR1. We measured RAR $\alpha$ protein expression in whole hippocampus homogenates and found no differences in RAR $\alpha$ expression between $Y$ and aged animals $\left(t_{(22)}=1.321, p=0.2\right.$; Fig. $\left.5 B\right)$. Interestingly, however, the expression of RAR $\alpha$ was significantly elevated in $\mathrm{Al}$ animals in comparison with both $\mathrm{Y}$ and $\mathrm{AU}$ rats $\left(F_{(2,21)}=6.218, p=0.008 ; \mathrm{Y}\right.$ vs $\mathrm{Al} p=0.021$, AU vs Al $p=0.013$; Fig. $5 C$ ). In addition, cognitive scores correlated with the expression of $\operatorname{RAR} \alpha$ protein across the $Y$ and aged rats $\left(n=24, r^{2}=0.184, p=0.037\right.$; Fig. $5 D$, gray line), such that animals with worse spatial memory showed higher RAR $\alpha$ expression. Among the aged animals alone, water maze performance failed to correlate significantly with $\operatorname{RAR} \alpha$ protein expression $\left(n=16, r^{2}=\right.$ 
$0.155, p=0.131$; Fig. $5 D$, black line). The strength of the association was nearly identical in both analyses, however, suggesting that the "aged only" result is less robust because of the decreased sample size and statistical power.

Non-genomic actions of RA signaling are mediated by RA receptors localized outside of the nucleus. We were specifically interested in the presence of RAR $\alpha$ in the synaptosome preparations, because non-nuclear RAR $\alpha$ acts as a mRNA granule containing GluR1 receptor mRNA. Therefore, we measured RAR $\alpha$ protein levels in whole hippocampus synaptosome fractions. Similar to results for the whole cell lysates, we found no differences in RAR $\alpha$ protein presence $\left(t_{(18)}=1.385, p=0.18\right.$; Fig. $\left.5 E\right)$. However, Al animals displayed increased synaptosome $\operatorname{RAR} \alpha$ content relative to $Y$ and $A U$ rats $\left(F_{(2,17)}=6.561, p=0.008\right.$; $Y$ vs Al $p=0.026$, AU vs Al $p=0.014$; Fig. $5 F$, also similar to the pattern in whole lysates. Additionally, synaptosome RA receptor expression positively correlated with spatial memory performance among the $\mathrm{Y}$ and aged rats, with higher $\mathrm{LI}$ scores (i.e., poor memory) associated with increased RAR $\alpha$ protein expression $\left(n=20, r^{2}=0.312, p=0.011\right.$; Fig. $5 G$, gray line). A similar positive correlation was also observed when the aged animals were considered alone in the analysis $\left(n=15, r^{2}=0.314, p=0.030\right.$; Fig. 5G, black line). These results indicate that RAR $\alpha$ expression is increased selectively in aged animals with memory impairment in both whole cell and synaptosome preparations. Among the aged rats, levels of this receptor localized to the synaptosome compartment were coupled with individual differences in hippocampal memory.

\section{Hippocampal FMRP protein is increased in aged animals}

Next, we examined FMRP protein expression, which is required for the translation of GluR1 mRNA. We found significantly increased levels of FMRP protein in the aged hippocampus $\left(t_{(22)}=3.27, p=0.0035\right.$; Fig. $\left.6 B\right)$. Al values were elevated relative to $Y$ rats $\left(F_{(2,21)}=7.202, p=0.004\right.$; $Y$ vs Al $p=0.003$; Fig. $6 C$ ), whereas results for AU were intermediate and failed to differ from either $\mathrm{Y}$ or $\mathrm{Al}$ (Fig. 6C). FMRP protein levels failed to correlate with LI scores, and overall, the data point to a general age-related increase in hippocampal FMRP.

\section{Cellular and synaptosome GluR1 levels are increased in aged animals with memory impairment}

In the presence of FMRP, GluR1 mRNA is translated locally in a RAR $\alpha$ regulated manner, enhancing AMPA receptor synaptic expression and strength. We measured GluR1 receptor protein levels in whole cell lysates and associated synaptosome preparations. No differences were observed in GluR1 expression between the $Y$ and aged group $\left(t_{(22)}=0.776, p=0.446\right.$; Fig. $\left.6 D\right)$. However, GluR1 protein was significantly increased in $\mathrm{Al}$ animals compared with $\mathrm{AU}\left(F_{(2,21)}=4.161, p=0.030\right.$, AU vs Al $p=0.031$; Fig. $6 E$ ), although neither aged subgroup differed from Y. The correlation between GluR1 protein levels and spatial memory was not significant when the $Y$ and aged animals were considered together $\left(n=24, r^{2}=\right.$ $0.061, p=0.245$ Fig. $6 F$, gray line). However, a reliable correlation was observed among the aged animals $\left(n=16, r^{2}=\right.$ $0.248, p=0.050$; Fig. $6 F$, black line), where poor spatial memory (i.e., high LI scores) was associated with higher hippocampal GluR1 levels.

In the synaptosome fraction, we found higher GluR1 protein expression in the aged rats than $Y\left(t_{(18)}=3.104\right.$, $p=0.006$; Fig. 6G), and this effect appeared largely attributable to elevation among $\mathrm{Al}$ animals $\left(F_{(2,17)}=5.865\right.$, $p=0.012$; Y vs Al $p=0.009$; Fig. $6 H)$. Although we found no direct correlation between spatial memory performance and synaptosome GluR1 levels, the results suggest that ionotropic glutamate expression in hippocampus, in both the cytosol and synaptosome, is predominantly increased in Al rats.

\section{Discussion}

Research on the neurobiology of cognitive aging has traditionally focused on identifying differences between groups configured on the basis of chronological age. This approach, however, can obscure the increased individual variability that is a hallmark of aging in humans and animal models. Here, adopting a strategy validated in many previous studies (McQuail et al., 2018; Rapp et al., 1987, 2020), we explicitly capitalized on this variability to test whether changes in RA signaling are associated with differential cognitive outcomes in aging. The current evidence clearly documents that RA signaling in the hippocampus is disrupted across multiple levels of regulation in aged rats with memory deficits. Specifically, while levels of a key transporter of the substrate for RA (STRA6) were decreased in the aged hippocampus independent of cognitive status, changes in other components of the RA signaling pathway, including but not limited to synthesis and catabolism of RA (RALDH1, CYP26B1, RAR $\alpha$, FMRP, and GluR1), were selectively increased among aged animals with memory impairment. Levels of most of the affected RA signaling factors were reliably correlated with individual differences in spatial memory among aged rats. Although the specific mechanisms linking changes in RA signaling to disrupted memory-related plasticity remain to be determined, in the aggregate our results point to an overall increase in hippocampal RA signaling associated with age-related cognitive impairment. While previous studies have suggested that global RA decline leads to cognitive impairment (Etchamendy et al., 2001; Bonnet et al., 2008; Dumetz et al., 2020), our findings suggest that locally increased RA signaling is coupled with age-related cognitive decline, perhaps reflecting failed compensatory mechanisms. Alongside experimental design factors that might contribute to apparent discrepancies across studies, such as rat strain and diet, the current results highlight the importance of considering RA signaling in relation to individual variability in the cognitive outcome of aging. Nonetheless, a priority knowledge gap for future investigation is to explore the direction of causality, testing whether the observed effects of aging on RA signaling are a driver of, or response to, cognitive decline. 

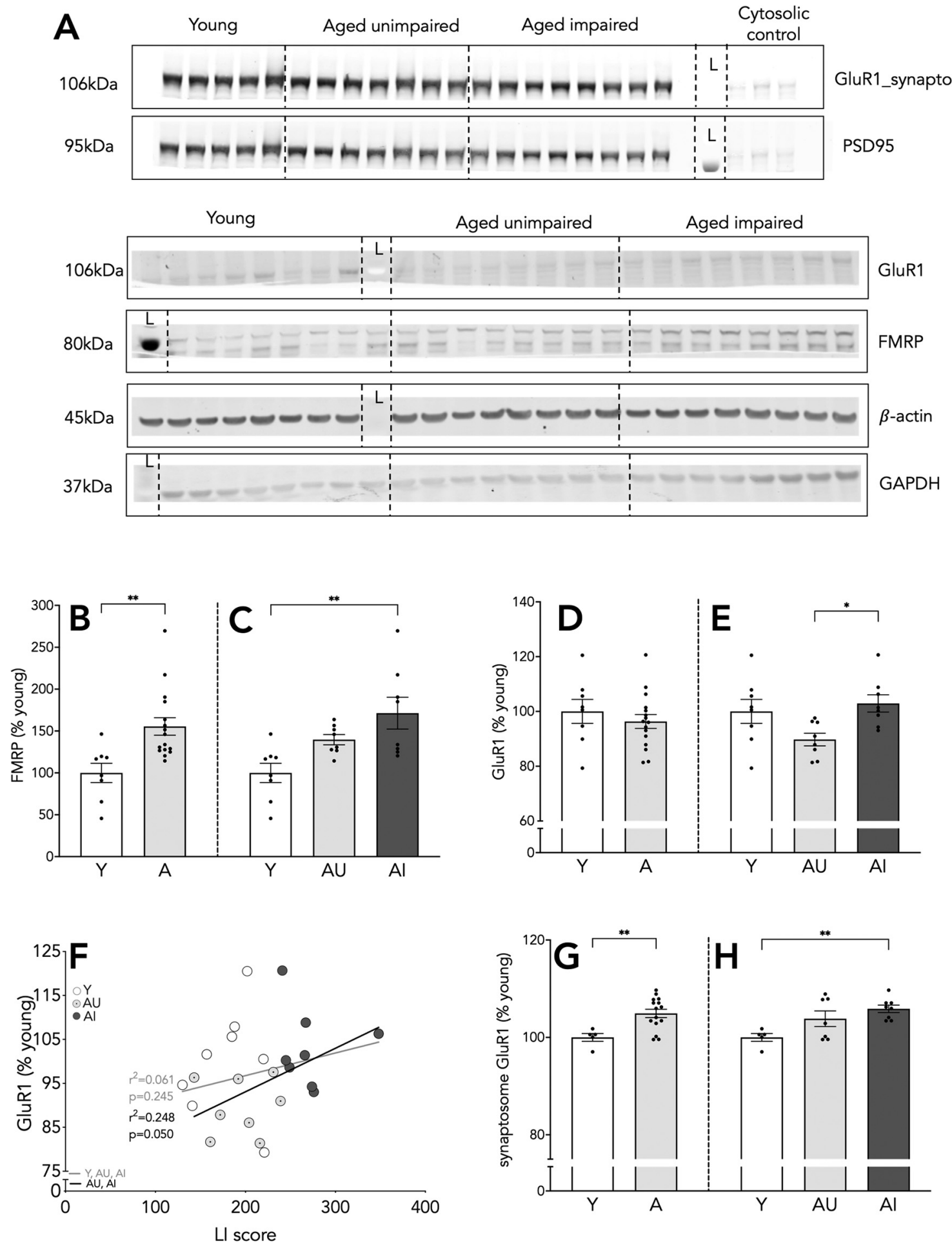

Figure 6. FMRP expression and cellular and dendritic expression of GluR1 in the hippocampus. Representative blots for proteins of interest $(\boldsymbol{A})$, FMRP expression relative to GAPDH (bottom four panels); cellular GluR1 expression relative to $\beta$-actin, and synaptosome GluR1 levels relative to PSD95 (top two panels); L stands for molecular ladder lane. Cytosolic fraction included as confirmation of the fractionation. Hippocampal expression of FMRP $(\boldsymbol{B}, \boldsymbol{C})$. Whole hippocampus $(\boldsymbol{D}, \boldsymbol{E})$ and synaptosome GluR1 protein levels $(\boldsymbol{G}, \boldsymbol{H})$. Correlation of cytosolic GluR1 protein expression with LI scores $(\boldsymbol{F})$. Results shown as bars with individual animal data plotted. Statistical analysis, unpaired two-tailed Student's $t$ test $(\boldsymbol{B}, \boldsymbol{D}, \boldsymbol{G})$, one-way ANOVA, with Tukey's multiple comparisons test $(\boldsymbol{C}, \boldsymbol{E}, \boldsymbol{H})$, and linear regression $\left(\boldsymbol{F}\right.$; all animals, gray line; aged animals, black line); C, cytosolic fraction; ${ }^{* \star} p<0.01$. Y $n=8$ and aged $n=16$ (AU $n=8, \mathrm{Al} n=8 ; \boldsymbol{B}-\boldsymbol{F}) ; \mathrm{Y} n=5$ and aged $n=15$ ( $\mathrm{AU} n=7, \mathrm{Al} n=8 ; \boldsymbol{G}, \boldsymbol{H})$. Error bars represent SEM. 


\section{Retinol availability in aged animals}

The availability of retinol in the circulation is essential for the synthesis of RA. Circulating levels of retinol are dependent on dietary availability of vitamin $A$ and are influenced by retinol storage in the liver, which is the largest storage site in the body (Napoli, 2012). The major pathway for retinol transport is through binding to RBP4/TTR complex (Li et al., 2014), and here, we used plasma RBP4 levels as a proxy for retinol content in the circulation. Animals in this study were maintained under identical conditions, ensuring that dietary retinol availability was constant and not the basis of the RBP4 differences seen between the aged groups.

Our results revealed significantly lower RBP4 plasma levels in AU animals compared with $\mathrm{Y}$. This is consistent with recent findings in humans showing decreased plasma RBP4 content in aged individuals (Soo Lee et al., 2013; Kocełak et al., 2018). Interestingly, Al animals had RBP4 levels comparable to $Y$ and significantly higher than $A U$ rats. The liver and kidney prominently influence RBP4, because of their role in synthesis and excretion, respectively. Plasma triglyceride levels, which are indicative of liver function, were comparable across groups, suggesting that impaired liver function is unlikely to drive changes in RBP4. Renal function also affects circulating RBP4 and can be assessed by plasma creatinine levels, where high levels are indicative of kidney disease. Kocełak et al. (2018) found increased circulating RBP4 in patients with chronic kidney disease. That study concluded that plasma levels of this RBP predominantly reflect poor kidney function and are only modestly sensitive to aging. Here, we found no age-related change in this binding protein. Overall, plasma RBP4 in aged animals strongly correlated with LI scores, where low levels were detected in AU plasma. Together, this pattern of results raises the possibility that the selective decrease of plasma RBP4 seen in AU rats may be a component of an adaptive cascade, reducing retinol availability in blood, and providing a potential biomarker of resilient cognitive aging.

Some studies have reported an increase in RBP4 with obesity and insulin resistance (Esteve et al., 2009; Shajarian et al., 2015), whereas others have found no relationship (Ûlgen et al., 2010; Kocełak et al., 2018). Aged rats in the present experiment did not display visible signs indicative of disrupted glucose regulation (e.g., increased water consumption and urination, or sharp weight gain), confirmed by normative circulating glucose levels. Additionally, plasma triglyceride content, a core component of the metabolic syndrome, was similar between groups. Creatinine levels further suggested that the rats were free of underlying renal disease that might influence RBP4 levels. Although the aged animals were significantly heavier and exhibited greater adiposity than Y, RBP4 levels were unrelated to body weight. Therefore, differences in plasma RBP4 among the aged rats were not secondary to weight gain or systemic metabolism change, and instead point to a potential RA influence on cognitive aging independent of metabolic aging.

\section{Global increase of RA metabolism in Al animals}

A significant role of RA in memory is emerging, complementing reports that, in the hippocampus, RA is involved in homeostatic synaptic scaling (Aoto et al., 2008; Sarti et al., 2012; Hsu et al., 2019). Although there is evidence that retinol signaling is altered in the aged brain (Enderlin et al., 1997; Touyarot et al., 2013), the involvement of RA in cognitive aging has received limited attention.

Our findings establish that protein levels of STRA6 receptor, which plays an important role in the retinol transport across blood-tissue barriers (Kelly et al., 2016), are decreased in the aged hippocampus. In brain, expression of this receptor is regulated by the availability of vitamin $\mathrm{A}$, and in tissues other than the eye, cytosolic retinol concentration is only partly regulated by STRA6 (Berry et al., 2013). In our model, age-related decline in hippocampal STRA6 expression does not appear to be a consequence of systemic change in retinol, as the results fail to parallel the observed changes in plasma RBP4 levels. Regardless of the mechanism, which remains to be determined, the reduction in STRA6 may reduce intracellular retinol availability. This is consistent with decreased retinoid brain levels in aged mice (Kelly et al., 2016).

We also examined the abundance of RA synthesizing and catabolizing enzymes in the hippocampus. Retinal dehydrogenase enzymes are responsible for the last step of RA synthesis. In the present experiments, RALDH1 expression was increased in aged animals, whereas RALDH3 levels were unchanged. Increased RALDH1 levels in the aged hippocampus contrast with reports of reduced retinol metabolism in other tissues (Etchamendy et al., 2003; Van Der Loo et al., 2004; Das et al., 2014) raising the possibility that the increase is a brain-specific response in aging. In the future it will be useful to extend the analysis to include the third RA synthesizing enzyme, RALDH2. The RA catabolic enzymes CYP26A1 and CYP26B1 are both expressed in the rat hippocampus (McCaffery and Simons, 2007; Stoney et al., 2016). CYP26A1 has greater catalytic activity for RA than CYP26B1 (Topletz et al., 2012), although CYP26B1 is more widely distributed in the brain (Stoney et al., 2016) and tightly regulates RA signaling during development (Abu-Abed et al., 2002). CYP26 gene expression is dynamically regulated by dietary retinol and RA from liver and extrahepatic tissues (Ray et al., 1997; Wang et al., 2002) While liver CYP26B1 is reportedly upregulated in aged subjects (Yamamoto et al., 2000), whether brain expression changes with age is unknown. Here, we found no difference in CYP26A1 between $Y$ and aged animals, whereas CYP26B1 protein levels increased with age. In line with the observed increase in synthesizing enzyme, the predicted consequence of enhanced RA presence is a net increase in CYP26B1-mediated catabolism.

One of the non-genomic functions of RA is mediated by $\operatorname{RAR} \alpha$, which undergoes active nuclear transport (Poon and Chen, 2008). This receptor is implicated in homeostatic synaptic scaling (Chen et al., 2014; Li et al., 2019), synaptic transmission in somatosensory cortex (Yee and Chen, 2016), and normal tactile sensory processing (Park 
et al., 2018). Here, we found significantly higher levels of RAR $\alpha$ in Al rats, in both cytosolic and synaptosome fractions from hippocampus, suggesting that non-genomic RA action is affected in these animals. The presumed consequence is greater $\operatorname{RAR} \alpha$ availability for RA to bind to and release GluR1 mRNA, increasing availability for translation.

The translation of GluR1 mRNA critically depends on FMRP. This protein is not directly related to the RA signaling pathway, but it is an important mediator of RA's downstream effects. An RNA-binding functional regulator, FMRP localizes to cytosolic membranes and the nucleus (Bostrom et al., 2016; Smidak et al., 2017), where it controls synaptic protein synthesis, modulating dendritic spine formation (Feng et al., 1997; Greenough et al., 2001; Weiler et al., 2004). Deficiency of FMRP leads to local protein synthesis-dependent endocytosis of GluR1 receptor (Nakamoto et al., 2007), and activation of GluRs influences dendritic FMRP localization (Antar, 2004). In contrast to previous reports (Singh et al., 2007; Smidak et al., 2017), our findings demonstrate modest but statistically reliable increases in hippocampal FMRP protein in aged rats, an effect predominantly attributable to $\mathrm{Al}$ rats. This increase, together with higher expression of GluR1, is positioned to potently influence excitatory neurotransmission in the hippocampus. Interestingly, pyramidal neurons in the hippocampal CA3 region of Al animals exhibit elevated firing rates (Wilson et al., 2005), and pharmacological treatments that reduce hyperactivity improve memory in both $\mathrm{Al}$ rats and $\mathrm{MCl}$ patients (Koh et al., 2010; Bakker et al., 2012). RA actions via $R A R \alpha$ are also known to cause downscaling of synaptic inhibition by FMRP-dependent removal of synaptic $\mathrm{GABA}_{\mathrm{A}}$ receptors (Sarti et al., 2013). It is possible, that altered GluR1 expression and network disinhibition lead to disrupted excitation/inhibition balance, which in turn may contribute to memory impairments observed in aged rats.

In conclusion, compelling evidence indicates that RA function extends well beyond metabolic control and includes regulation of memory-related synaptic plasticity. Here, we demonstrate that RA signaling in neurocognitive aging is affected at nearly all levels of regulation examined. We found a decrease in plasma RBP4 in aged animals without memory impairment. Net hippocampal RA signaling is likely increased in aged rats with cognitive impairment, reflecting in part greater synthesizing and catabolizing enzyme expression. Furthermore, we find increases in RAR $\alpha$, FMRP and GluR1 selectively in aged rats with memory impairments. These changes appear unrelated to metabolic aging, and instead most are specifically related to individual differences in the cognitive outcome of aging rather than chronological age. The importance of neuronal excitation/inhibition balance in relation to cognitive outcome has been highlighted in many studies and is the core of numerous neurologic diseases where altered RA signaling is implicated (Wołoszynowska-Fraser et al., 2020). Together, the current results lean in favor of increased RA signaling, potentially contributing to the excitation/inhibition imbalance that is prominently featured in age-related cognitive impairment. This work further extends the boundaries of RA function in brain, and specifically highlights the importance of considering aging effects in relation to individual variability in cognitive aging. Among potential future directions, a comprehensive account of RA signaling influences on neurocognitive aging will also require a parallel assessment of genomic pathway effects.

\section{References}

Abu-Abed S, MacLean G, Fraulob V, Chambon P, Petkovich M, Dollé $P$ (2002) Differential expression of the retinoic acid-metabolizing enzymes CYP26A1 and CYP26B1 during murine organogenesis. Mech Dev 110:173-177.

Antar LN, Afroz R, Dictenberg JB, Carroll RC, Bassell GJ (2004) Metabotropic glutamate receptor activation regulates fragile $X$ mental retardation protein and Fmr1 mRNA localization differentially in dendrites and at synapses. J Neurosci 24:2648-2655.

Aoto J, Nam Cl, Poon MM, Ting P, Chen L (2008) Synaptic signaling by all-trans retinoic acid in homeostatic synaptic plasticity. Neuron 60:308-320.

Bakker A, Krauss GL, Albert MS, Speck CL, Jones LR, Stark CE, Yassa MA, Bassett SS, Shelton AL, Gallagher M (2012) Reduction of hippocampal hyperactivity improves cognition in amnestic mild cognitive impairment. Neuron 74:467-474.

Berry DC, Jacobs H, Marwarha G, Gely-Pernot A, O'Byrne SM, DeSantis D, Klopfenstein M, Feret B, Dennefeld C, Blaner WS, Croniger CM, Mark M, Noy N, Ghyselinck NB (2013) The STRA6 receptor is essential for retinol-binding protein-induced insulin resistance but not for maintaining vitamin a homeostasis in tissues other than the eye. J Biol Chem 288:24528-24539.

Blomhoff R, Blomhoff HK (2006) Overview of retinoid metabolism and function. J Neurobiol 66:677-686.

Bonnet E, Touyarot K, Alfos S, Pallet V, Higueret P, Abrous DN (2008) Retinoic acid restores adult hippocampal neurogenesis and reverses spatial memory deficit in vitamin A deprived rats. PLoS One 3:e3487.

Bostrom C, Yau S, Majaess N, Vetrici M, Gil-Mohapel J, Christie BR (2016) Hippocampal dysfunction and cognitive impairment in fragile-X syndrome. Neurosci Biobehav Rev 68:563-574.

Castellano JF, Fletcher BR, Kelley-Bell B, Kim DH, Gallagher M, Rapp PR (2012) Age-related memory impairment is associated with disrupted multivariate epigenetic coordination in the hippocampus. PLoS One 7:e33249.

Chen L, Lau AG, Sarti F (2014) Synaptic retinoic acid signaling and homeostatic synaptic plasticity. Neuropharmacology 78:3-12.

Chen N, Napoli JL (2008) All-trans-retinoic acid stimulates translation and induces spine formation in hippocampal neurons through a membrane-associated RARalpha. FASEB J 22:236-245.

Chen N, Onisko B, Napoli JL (2008) The nuclear transcription factor RARalpha associates with neuronal RNA granules and suppresses translation. J Biol Chem 283:20841-20847.

Das BC, Thapa P, Karki R, Das S, Mahapatra S, Liu TC, Torregroza I, Wallace DP, Kambhampati S, Van Veldhuizen P, Verma A, Ray SK, Evans T (2014) Retinoic acid signaling pathways in development and diseases. Bioorg Med Chem 22:673-683.

Dumetz F, Buré C, Alfos S, Bonneu M, Richard E, Touyarot K, Marie A, Schmitter JM, Bosch-Bouju C, Pallet V (2020) Normalization of hippocampal retinoic acid level corrects age-related memory deficits in rats. Neurobiol Aging 85:1-10.

Enderlin V, Pallet V, Alfos S, Dargelos E, Jaffard R, Garcin H, Higueret P (1997) Age-related decreases in mRNA for brain nuclear receptors and target genes are reversed by retinoic acid treatment. Neurosci Lett 229:125-129.

Esteve E, Ricart W, Fernández-Real JM (2009) Adipocytokines and insulin resistance: the possible role of lipocalin-2, retinol binding protein-4, and adiponectin. Diabetes Care 32:S362-S367. 
Etchamendy N, Enderlin V, Marighetto A, Vouimba RM, Pallet V, Jaffard R, Higueret P (2001) Alleviation of a selective age-related relational memory deficit in mice by pharmacologically induced normalization of brain retinoid signaling. J Neurosci 21:64236429.

Etchamendy N, Enderlin V, Marighetto A, Pallet V, Higueret $\mathrm{P}$, Jaffard R (2003) Vitamin A deficiency and relational memory deficit in adult mice: relationships with changes in brain retinoid signalling. Behav Brain Res 145:37-49.

Feng Y, Gutekunst CA, Eberhart DE, Yi H, Warren ST, Hersch SM (1997) Fragile $X$ mental retardation protein: nucleocytoplasmic shuttling and association with somatodendritic ribosomes. J Neurosci 17:1539-1547.

Fletcher BR, Hill GS, Long JM, Gallagher M, Shapiro ML, Rapp PR (2014) A fine balance: regulation of hippocampal Arc/Arg3.1 transcription, translation and degradation in a rat model of normal cognitive aging. Neurobiol Learn Mem 115:58-67.

Gallagher M, Burwell R, Burchinal M (1993) Severity of spatial learning impairment in aging: development of a learning index for performance in the Morris water maze. Behav Neurosci 107:618-626.

Greenough WT, Klintsova AY, Irwin SA, Galvez R, Bates KE, Weiler IJ (2001) Synaptic regulation of protein synthesis and the fragile $X$ protein. Proc Natl Acad Sci USA 98:7101-7106.

Groth RD, Tsien RW (2008) A role for retinoic acid in homeostatic plasticity. Neuron 60:192-194.

Haberman RP, Quigley CK, Gallagher M (2012) Characterization of $\mathrm{CpG}$ island DNA methylation of impairment-related genes in a rat model of cognitive aging. Epigenetics 7:1008-1019.

Hsu Y, Li J, Wu D, Südhof TC, Chen L (2019) Synaptic retinoic acid receptor signaling mediates $\mathrm{mTOR}$-dependent metaplasticity that controls hippocampal learning. Proc Natl Acad Sci USA 116:7113-7122.

Kanai M, Raz A, Goodman DS (1968) Retinol-binding protein: the transport protein for vitamin $\mathrm{A}$ in human plasma. $\mathrm{J}$ Clin Invest 47:2025-2044.

Kelly M, Widjaja-Adhi MAK, Palczewski G, von Lintig J (2016) Transport of vitamin A across blood-tissue barriers is facilitated by STRA6. FASEB J 30:2985-2995.

Kocełak P, Owczarek A, Boz ${ }^{2}$ entowicz-Wikarek M, Brzozowska A, Mossakowska M, Grodzicki T, Wieôcek A, Chudek J, OlszaneckaGlinianowicz M (2018) Plasma concentration of retinol binding protein 4 (RBP4) in relation to nutritional status and kidney function in older population of PolSenior Study. Adv Med Sci 63:323-328.

Koh MT, Haberman RP, Foti S, Mccown TJ, Gallagher M (2010) Treatment strategies targeting excess hippocampal activity benefit aged rats with cognitive impairment. Neuropsychopharmacology 35:1016-1025.

Lee HK, Min SS, Gallagher M, Kirkwood A (2005) NMDA receptor-independent long-term depression correlates with successful aging in rats. Nat Neurosci 8:1657-1659.

Li J, Park E, Zhong LR, Chen L (2019) Homeostatic synaptic plasticity as a metaplasticity mechanism - a molecular and cellular perspective. Curr Opin Neurobiol 54:44-53.

Li Y, Wongsiriroj N, Blaner WS (2014) The multifaceted nature of retinoid transport and metabolism. Hepatobiliary Surg Nutr 3:126139.

Maden M (2007) Retinoic acid in the development, regeneration and maintenance of the nervous system. Nat Rev Neurosci 8:755-765.

Maei HR, Zaslavsky K, Teixeira CM, Frankland PW (2009) What is the most sensitive measure of water maze probe test performance? Front Integr Neurosci 3:1-9.

Maghsoodi B, Poon MM, Nam Cl, Aoto J, Ting P, Chen L (2008) Retinoic acid regulates RARalpha-mediated control of translation in dendritic RNA granules during homeostatic synaptic plasticity. Proc Natl Acad Sci USA 105:16015-16020.

McCaffery P, Simons C (2007) Prospective teratology of retinoic acid metabolic blocking agents (RAMBAs) and loss of CYP26 activity. Curr Pharm Des 13:3020-3037.
McQuail JA, Johnson SA, Burke SN, Bizon JL (2018) Rat models of cognitive aging. In: Conn's handbook of models for human aging, Ed 2, pp 211-230. Amsterdam: Elsevier.

Mingaud F, Mormede C, Etchamendy N, Mons N, Niedergang B, Wietrzych M, Pallet V, Jaffard R, Krezel W, Higueret P, Marighetto A (2008) Retinoid hyposignaling contributes to aging-related decline in hippocampal function in short-term/working memory organization and long-term declarative memory encoding in mice. $J$ Neurosci 28:279-291.

Myrum C, Rossi SL, Perez EJ, Rapp PR (2019) Cortical network dynamics are coupled with cognitive aging in rats. Hippocampus 29:1165-1177.

Nakamoto M, Nalavadi V, Epstein MP, Narayanan U, Bassell GJ, Warren ST (2007) Fragile X mental retardation protein deficiency leads to excessive mGluR5-dependent internalization of AMPA receptors. Proc Natl Acad Sci USA 104:15537-15542.

Napoli JL (2012) Physiological insights into all-trans-retinoic acid biosynthesis. Biochim Biophys Acta 1821:152-167.

Nomoto M, Takeda Y, Uchida S, Mitsuda K, Enomoto H, Saito K, Choi T, Watabe AM, Kobayashi S, Masushige S, Manabe T, Kida S (2012) Dysfunction of the RAR/RXR signaling pathway in the forebrain impairs hippocampal memory and synaptic plasticity. Mol Brain 5:8.

O’Byrne SM, Blaner WS (2013) Retinol and retinyl esters: biochemistry and physiology. J Lipid Res 54:1731-1743.

Palha JA (2002) Transthyretin as a thyroid hormone carrier: function revisited. Clin Chem Lab Med 40:1292-1300.

Park E, Tjia M, Zuo Y, Chen L (2018) Postnatal ablation of synaptic retinoic acid signaling impairs cortical information processing and sensory discrimination in mice. J Neurosci 38:3028-3017.

Poon MM, Chen L (2008) Retinoic acid-gated sequence-specific translational control by RAR. Proc Natl Acad Sci USA 105:2030320308.

Rapp PR, Gallagher M (1996) Preserved neuron number in the hippocampus of aged rats with spatial learning deficits. Proc Natl Acad Sci USA 93:9926-9930.

Rapp PR, Rosenberg RA, Gallagher M (1987) An evaluation of spatial information processing in aged rats. Behav Neurosci 101:3-12.

Rapp PR, Bañuelos C, Myrum C (2020) Neuroadaptive trajectories of healthy mindspan: from genes to neural networks. In: The Cambridge handbook of cognitive aging, pp 62-81. Cambridge: Cambridge University Press.

Ray WJ, Bain G, Yao M, Gottlieb DI (1997) CYP26, a novel mammalian cytochrome P450, is induced by retinoic acid and defines a new family. J Biol Chem 272:18702-18708.

Sarti F, Schroeder J, Aoto J, Chen L (2012) Conditional RAR $\alpha$ knockout mice reveal acute requirement for retinoic acid and $\operatorname{RAR} \alpha$ in homeostatic plasticity. Front Mol Neurosci 5:1-12.

Sarti F, Zhang Z, Schroeder J, Chen L (2013) Rapid suppression of inhibitory synaptic transmission by retinoic acid. J Neurosci 33:11440-11450

Segovia G, Porras A, Del Arco A, Mora F (2001) Glutamatergic neurotransmission in aging: a critical perspective. Mech Ageing Dev 122:1-29.

Shajarian M, Rafiee L, Naji-Esfahani H, Haghjooy-Javanmard S, Nizal S (2015) Association of RBP4 gene variants with adverse lipid profile and obesity. Gene 561:1-5.

Shearer KD, Stoney PN, Morgan PJ, McCaffery PJ (2012) A vitamin for the brain. Trends Neurosci 35:733-741.

Singh K, Gaur P, Prasad S (2007) Fragile x mental retardation (Fmr-1) gene expression is down regulated in brain of mice during aging. Mol Biol Rep 34:173-181.

Smidak R, Sialana FJ, Kristofova M, Stojanovic T, Rajcic D, Malikovic J, Feyissa DD, Korz V, Hoeger H, Wackerlig J, Mechtcheriakova D, Lubec G (2017) Reduced levels of the synaptic functional regulator FMRP in dentate gyrus of the aging sprague-dawley rat. Front Aging Neurosci 9:1-10.

Soden ME, Chen L (2010) Fragile X protein FMRP is required for homeostatic plasticity and regulation of synaptic strength by retinoic acid. J Neurosci 30:16910-16921. 
Soo Lee E, Sae YJ, Soo LJ, Yadav D, Joo CE, Sik CY, Min KH, Hee CC (2013) Differences in adipokine and hepatokine levels among non-diabetic population classified by age and sex. J Life Med 3:62-67

Spiegel AM, Koh MT, Vogt NM, Rapp PR, Gallagher M (2013) Hilar interneuron vulnerability distinguishes aged rats with memory impairment. J Comp Neurol 521:3508-3523.

Stoney PN, Fragoso YD, Saeed RB, Ashton A, Goodman T, Simons C, Gomaa MS, Sementilli A, Sementilli L, Ross AW, Morgan PJ, McCaffery PJ (2016) Expression of the retinoic acid catabolic enzyme CYP26B1 in the human brain to maintain signaling homeostasis. Brain Struct Funct 221:3315-3326.

Thompson SJ, Sargsyan A, Lee SA, Yuen JJ, Cai J, Smalling R, Ghyselinck N, Mark M, Blaner WS, Graham TE (2017) Hepatocytes are the principal source of circulating RBP4 in mice. Diabetes 66:58-63.

Tomás Pereira I, Burwell RD (2015) Using the spatial learning index to evaluate performance on the water maze. Behav Neurosci 129:533-539.

Topletz AR, Thatcher JE, Zelter A, Lutz JD, Tay S, Nelson WL, Isoherranen N (2012) Comparison of the function and expression of CYP26A1 and CYP26B1, the two retinoic acid hydroxylases. Biochem Pharmacol 83:149-163.

Touyarot K, Bonhomme D, Roux P, Alfos S, Lafenêtre P, Richard E, Higueret P, Pallet V (2013) A mid-life vitamin A supplementation prevents age-related spatial memory deficits and hippocampal neurogenesis alterations through CRABP-I. PLoS One 8:e72101.

Ûlgen F, Herder C, Kühn MC, Willenberg HS, Schott M, Scherbaum WA, Schinner S (2010) Association of serum levels of retinol-binding protein 4 with male sex but not with insulin resistance in obese patients. Arch Physiol Biochem 116:57-62.

Van Der Loo B, Labugger R, Aebischer CPCP, Bachschmid M, Spitzer V, Kilo J, Altwegg L, Ullrich V, Lüscher TFTF (2004) Age-related changes of vitamin A status. J Cardiovasc Pharmacol 43:2630.
Vieira M, Saraiva MJ (2014) Transthyretin: a multifaceted protein. Biomol Concepts 5:45-54.

Wang Y, Zolfaghari R, Ross AC (2002) Cloning of rat cytochrome P450RAI (CYP26) CDNA and regulation of its gene expression by all-trans-retinoic acid in vivo. Arch Biochem Biophys 401:235243.

Weiler IJ, Spangler CC, Klintsova AY, Grossman AW, Kim SH, Bertaina-Anglade V, Khaliq H, de Vries FE, Lambers FAE, Hatia F, Base CK, Greenough WT (2004) Fragile X mental retardation protein is necessary for neurotransmitter-activated protein translation at synapses. Proc Natl Acad Sci USA 101:17504-17509.

Wilson IA, Ikonen S, Gallagher M, Eichenbaum H, Tanila H (2005) Age-associated alterations of hippocampal place cells are subregion specific. J Neurosci 25:6877-6886.

Wołoszynowska-Fraser MU, Kouchmeshky A, McCaffery P (2020) Vitamin $A$ and retinoic acid in cognition and cognitive disease. Annu Rev Nutr 40:247-272.

Yee A, Chen L (2016) Differential regulation of spontaneous and evoked inhibitory synaptic transmission in somatosensory cortex by retinoic acid. Synapse 70:445-452.

Xun C, Zhao Y, Wang W, Chen C (2018) Circulating RBP4 increase and its diagnosis of chronic kidney disease. Ann Clin Lab Sci 48:205-207.

Yamamoto Y, Zolfaghari R, Ross AC (2000) Regulation of CYP26 (cytochrome P450RAl) mRNA expression and retinoic acid metabolism by retinoids and dietary vitamin $A$ in liver of mice and rats. FASEB J 14:2119-2127.

Yang Q, Graham TE, Mody N, Preitner F, Peroni OD, Zabolotny JM, Kotani K, Quadro L, Kahn BB (2005) Serum retinol binding protein 4 contributes to insulin resistance in obesity and type 2 diabetes. Nature 436:356-362.

Yang YJ, Chen HB, Wei B, Wang W, Zhou PL, Zhan JQ, Hu MR, Yan K, Hu B, Yu B (2015) Cognitive decline is associated with reduced surface GluR1 expression in the hippocampus of aged rats. Neurosci Lett 591:176-181. 